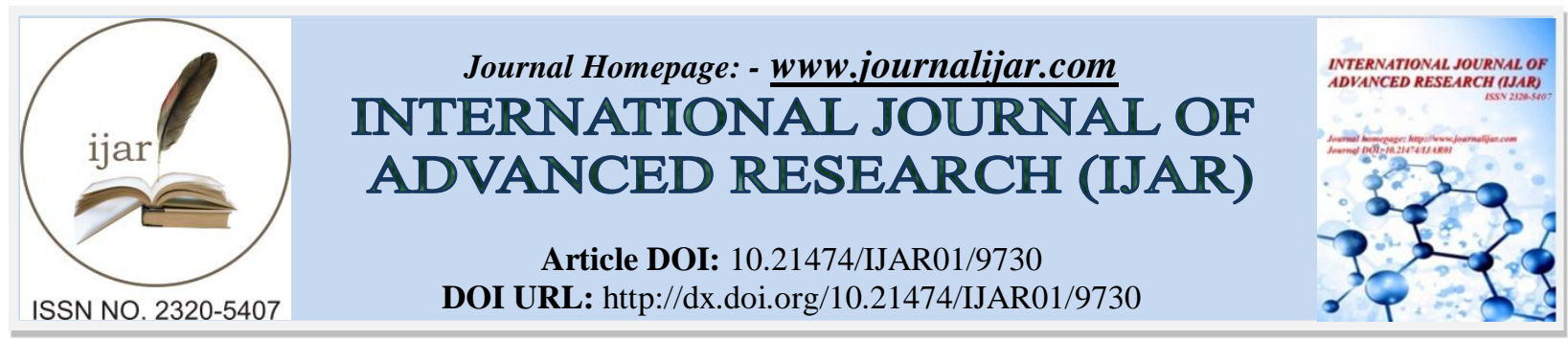

RESEARCH ARTICLE

\title{
PHYSICAL AND PHYTO-CHEMICAL EVALUATION OF STEM OF SESAMUM INDICUM LINN (TILA
} NALA).

Radhika M.P ${ }^{1}$ and Dr.Jollykutty Eapen ${ }^{2}$.

1. PG Scholar, Dept of Dravyagunavijnana, Government Ayurveda College, Thiruvananthapuram, Kerala.

2. Professor \& HOD, Dept of Dravyagunavijnana, Government Ayurveda College, Thiruvananthapuram, Kerala.

\section{Manuscript Info}

Manuscript History

Received: 09 July 2019

Final Accepted: 12 August 2019

Published: September 2019

Key words:-

Tila nala,Sesamum indicum Linn,TLC,HPTLC.

\section{Abstract}

Sesamum indicum Linn. is an erect pubescent annual herb commonly known as sesame plant. The uses of Tila nala kshara (alkali preparation from stem or stalk of Sesamum indicum Linn.) is mentioned in Ayurvedic text books like Cakradatta,Yogaratnakara etc. Ascertaining the identity,genuineness and purity of herbal drugs has an important role in the maintenance of the quality of the drug and its formulations. The present study was undertaken to assess the preliminary physical and phyto-chemical parameters of the stem of Sesamum indicum Linn. The preliminary physical and phyto-chemical analysis includes analysing parameters such as the foreign body matter, moisture content, ash values, fibre content, volatile oil content, sugar content, different extractive values, qualitative analysis, heavy metal analysis by Atomic Absorption Spectroscopy and chromatographic techniques like TLC and HPTLC. The preliminary physical and phyto-chemical characters observed in this study may help in standardisation,identification and in carrying out further research in Sesamum indicum Linn.

Copy Right, IJAR, 2019,. All rights reserved.

\section{Introduction:-}

Sesamum indicum Linn (Tila) is a sacred plant among medicinal herbs in India since ancient times. According to Ayurvedic pharmacopeia of India, Tila is Sesamum indicum Linn. (Family, Pedaliaceae), a herbaceous plant extensively cultivated throughout India in the plains and upto an altitude of $1200 \mathrm{~m}$ for its seeds ${ }^{1}$.Usually after the harvest of sesame seed(Tila beeja), its stalk or stem (nala) is discarded. Many of the Ayurvedic texts explained seeds as the useful part of Tila plant. So, data related to Tila seeds . The uses of Tila nala kshara( alkali preparation from stalk of Sesamum indicum Linn.) is mentioned in Ayurvedic text books like Cakradatta ${ }^{2}$, Yoga ratnakara ${ }^{3}$ etc. But characters, properties and uses of stem of Tila plant(tila nala) are not available.

The objective of the present study is to evaluate the preliminary physical and phyto-chemical characters of the stem of Sesamum indicum Linn (Tila nala).

Corresponding Author:-Radhika M.P.

Address:-PG Scholar, Dept of Dravyagunavijnana, Government Ayurveda College,Thiruvananthapuram, Kerala. 


\section{Materials And Methods:- Collection of the drug}

Genuine Sesamum plant stem samples were procured from natural habitat from Maduri, Tamilnadu for urinary calculii and the sample was authenticated by Botanist, Drug Standardisation Unit, Govt Ayurveda College Thiruvananthapuram. They were shade dried and packed in zip lock polythene bag.

\section{Study setting}

Drug standardisation unit, Govt.Ayurveda college, Thiruvananthapuram.

\section{Physico-chemical evaluation}

Physico-chemical analysis including analyzing parameters such as the foreign body matter, moisture content, ash values, fibre content, volatile oil content, sugar content, different extractive values, qualitative analysis, heavy metal analysis by Atomic Absorption Spectroscopy and chromatographic techniques like TLC, HPTLC were done. The procedures were done as per guidelines mentioned in Ayurvedic Pharmacopoeia of India ${ }^{4}$.

\section{Preparation of the sample drug}

The stalk of the Sesamum indicum Linn (sufficient quantity) was collected, cleaned and dried in shade. After drying, the coarsely powdered drug was kept in air tight containers.

\section{Reagents used}

Xylene, dilute Hydrochloric acid, concentrated hydrochloric acid, concentrated sulphuric acid, Acetic anhydride, Cyclohexane, Acetone, Petroleum ether, Chloroform, Ethyl acetate, Magnesium ribbon, neutral Ferric chloride, Benzene, Ethyl acetate, Acetic acid, Potassium permagnante, Ferric alum, Ethanol, Lead acetate, Sodium oxalate, Ethanol, Sodium bicarbonate, Fehling's solution, Dragendroff's reagent and distilled water.

\section{Apparatus}

Dean and Stark's apparatus, Clevenger apparatus, Soxhlet apparatus, silica crucible, Bunsen burner,round bottomed flask, measuring jars, beakers, conical flask, funnel, glass rods, watch glass, electronic balance etc.

\section{Results And Discussion:-}

The phytochemical screening of the drug Sesamum indicum Linn was done. Total ash represents the inorganic salts present in the drug. Acid insoluble salts represent the contamination of earthy material. The extractive values help to evaluate the solubility of constituents in a particular solvent.

\section{Results of Preliminary phytochemical analysis of stem}

In physical analysis, foreign matter, volatile oil content, moisture content, extractive values, ash value, fibre content and sugar values were estimated. The values of dried stem of Sesamum indicum Linn were estimated in Table no: The volatile oil content was found to be nil.

\section{Results of qualitative chemical analysis of alcoholic extract}

The qualitative analysis revealed the presence of steroids, phenols, alkaloids, Tannin in ethanolic extract of dried stem of Sesamum indicum Linn.and that was mentioned in Table no: 2. Qualitative chemical analysis has got supreme importance since pharmacological action and therapeutic properties of the drug mainly depends on these chemical constituents. Testing for these phyto constituents helps in determining the quality of the drug.

\section{Results of TLC and HPTLC}

TLC and HPTLC studies were also done, the best separation was achieved using Toluene: Ethyl acetate: Formic acid in the ratio 9:1:0.2. The spots obtained in TLC gives a rough idea about the study plant constituents. In TLC profile, 5 spots were obtained in the UV region (Table no: 3). In HPTLC, 6 spots were obtained in UV region with same solvent system (Table no: 4). The Rf values of spots obtained in TLC and HPTLC with the same solvent system was tabulated in Table no: $3 \&$ Table no: 4 respectively.

\section{Results of Atomic Absorption Spectroscopy}


Heavy metal analysis of the drug was carried out using Atomic Absorption Spectroscopy. Four heavy metals, Lead, Cadmium, Iron, Zinc contents were found within the permissible limits (table no: 5). Thus the drug is safe for internal administration.

Table no 1:-Preliminary phytochemical analysis of stem of Sesamum indicum Linn

\begin{tabular}{|c|c|c|c|}
\hline Sl no & \multicolumn{2}{|c|}{ Name of experiment } & Stem of Sesamum indicum Linn \\
\hline 1 & \multicolumn{2}{|l|}{ Forign matter } & NIL \\
\hline 2 & \multicolumn{2}{|c|}{ Moisture content } & $8 \%$ \\
\hline 3 & \multicolumn{2}{|c|}{ Volatile oil content } & NIL \\
\hline 4 & \multicolumn{2}{|l|}{ Total ash } & $3.30 \%$ \\
\hline 5 & \multicolumn{2}{|c|}{ Acid insoluble ash } & $0.34 \%$ \\
\hline 6 & \multicolumn{2}{|c|}{ Hot water soluble extractive } & $3.51 \%$ \\
\hline 7 & \multicolumn{2}{|c|}{ Alcohol soluble extractives } & $2.04 \%$ \\
\hline 8 & \multicolumn{2}{|c|}{ Fibre content } & $57.88 \%$ \\
\hline \multirow[t]{2}{*}{9} & \multirow[t]{2}{*}{ Sugar content } & Reducing sugar & $1.66 \%$ \\
\hline & & Total sugar & $1.66 \%$ \\
\hline
\end{tabular}

Table no2:-The results of qualitative chemical analysis of alcoholic extract

\begin{tabular}{|l|l|l|}
\hline Sl no & Chemical constituent & Status \\
\hline 1 & Alkaloid & Present \\
\hline 2 & Steroid & Present \\
\hline 3 & Phenols & Present \\
\hline 4 & Flavanoids & Present \\
\hline 5 & Tannin & Present \\
\hline
\end{tabular}

Table no 3:-showing results of Rf values of spots obtained in TLC

\begin{tabular}{|l|l|l|l|l|}
\hline Solvent system & Extract & Spot detection & No of spots & Rf value \\
\hline Toluene:Ethyl acetate: Formic & & & & 0.19 \\
acid (9:1:0.2) & Ethanol & UV & 5 & 0.25 \\
& & & 0.50 \\
& & & & 0.58 \\
\end{tabular}

Table no 4:-showing results of Rf values of different spots obtained in HPTLC

\begin{tabular}{|l|l|l|l|}
\hline Solvent system & Extract & No of spots & Rf value \\
\hline & & 6 & 0.12 \\
Toluene:Ethyl acetate: Formic acid (9:1:0.2) & Ethanol & & 0.18 \\
& & & 0.24 \\
& & & 0.34 \\
& & & 0.46 \\
\hline
\end{tabular}

Table no 5:-showing results of atomic absorption spectroscopy

\begin{tabular}{|l|l|l|}
\hline Heavy metal concentration in ppm & Sample (ppm) & Permissible Limit \\
\hline Lead & 0.08 & 10 \\
\hline Cadmium & 0.03 & 0.3 \\
\hline Iron & 2.36 & 20 (for food) \\
\hline Zinc & 0.53 & 27.4 \\
\hline
\end{tabular}


Fig 1:-Dried stem of Sesamum indicum Linn

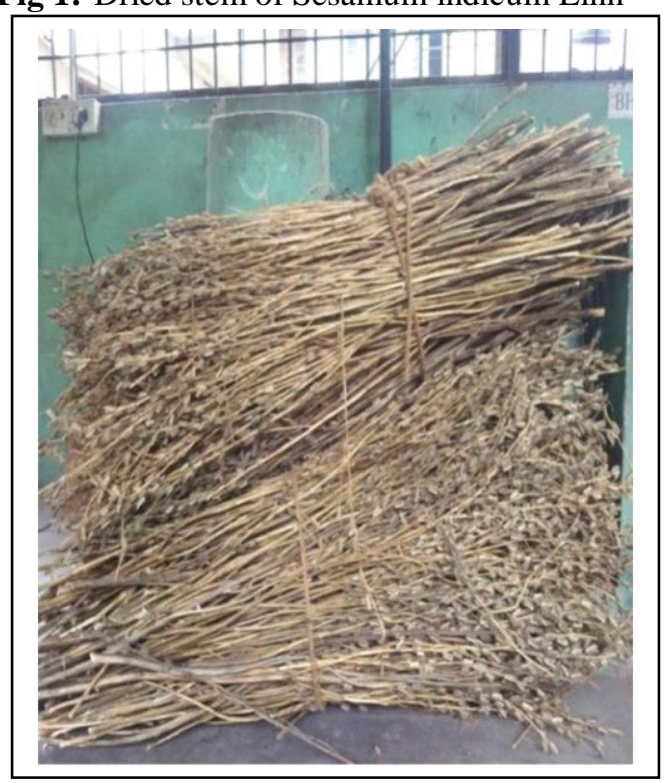

Fig 2:-HPLTC Plate with solvent system Toluene:Ethyl acetate: Formic acid (9:1:0.2)

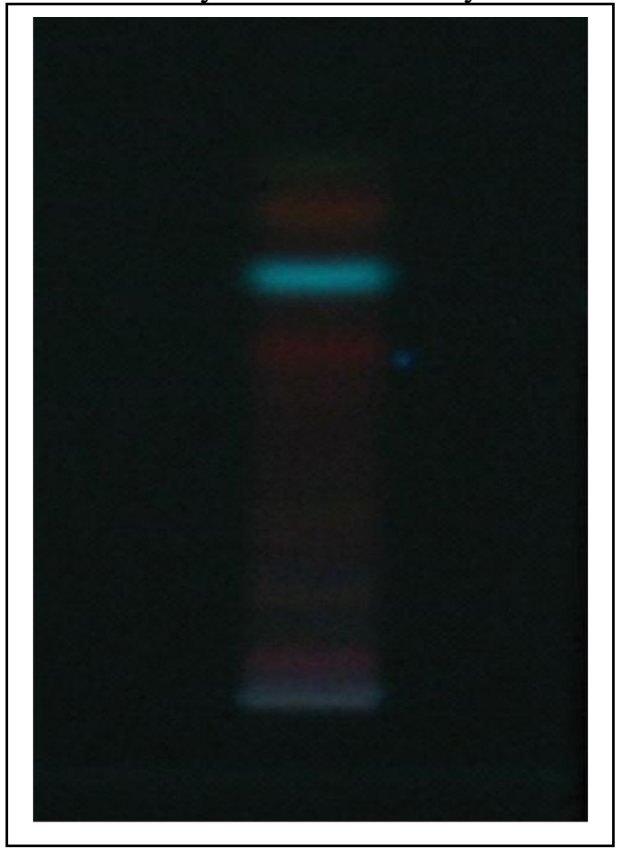

\section{Conclusion:-}

Sesamum indicum Linn (Tila) is a herbaceous plant extensively cultivated throughout India in the plains and upto an altitude of $1200 \mathrm{~m}$ for its seeds. Usually after the harvest of sesame seed (Tila beeja), its stalk or stem (nala) is discarded. The uses of Tila nala kshara( alkali preparation from stalk of Sesamum indicum Linn.) is mentioned in Ayurvedic text books. But characters, properties and uses of stem of Tila plant (tila nala) are not available. In the present study, various phytochemical screening was carried out as per the standard procedure. Results of phytochemical sreening may help in identity and standardisation of drug. Till date no reference values is available 
regarding physico-chemical analysis of Sesamum stem. So the values obtained in the study as mentioned in Table no: 1,Table no: 2,Table no: 3 and Table no: 4 can be taken as a reference for further studies and in future may help in enriching API (Ayurvedic Pharmacopoeia of India).

\section{References:-}

1. The Ayurveda pharmacopoeia of India,.Govt. of India. Ministry of health and Family welfare, Dept. of ISM\&H (AYUSH), New Delhi;2007, part I,vol 4; p:1264.

2. Dr.G.prabhakara rao, G. CAKRADATTA (CIKITSA SANGRAHA) Of Cakrapanidatta,Sanskrit Text with English Translation. (FIRST EDITION). VARANASI-221001(UP) (INDIA): CHAUKHAMBHA ORIENTALIA; 2014; p: 296.

3. Drmadham shetty suresh babu. Yogaratnakara(Sanskrit text with translation and explanatory notes),voLII. (First ed.). Varanasi (India): Chowkhamba sanskrit series office,varanasi; 2008.p:216.

4. The Ayurvedic Pharmacopoeia of India, Govt. of India. Ministry of health and Family welfare, Dept. of ISM\&H(AYUSH), New Delhi,2001,Part 1,Vol.3,227-240. 